\title{
RESEARCH
}

Open Access

\section{Chidamide increases the sensitivity of refractory or relapsed acute myeloid leukemia cells to anthracyclines via} regulation of the HDAC3 -AKT-P21-CDK2 signaling pathway

Hao Wang ${ }^{1 \dagger}$, Yu-chen Liu ${ }^{1 \dagger}$, Cheng-ying Zhu ${ }^{1+}$, Fei Yan², Meng-zhen Wang ${ }^{1}$, Xiao-su Chen ${ }^{3}$, Xiao-kai Wang ${ }^{4}$,

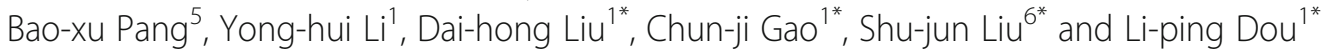

\begin{abstract}
Background: Induction therapy for acute myeloid leukemia (AML) is an anthracycline-based chemotherapy regimen. However, many patients experience a relapse or exhibit refractory disease (R/R). There is an urgent need for more effective regimens to reverse anthracycline resistance in these patients.

Methods: In this paper, Twenty-seven R/R AML patients with anthracycline resistance consecutively received chidamide in combination with anthracycline-based regimen as salvage therapy at the Chinese PLA General Hospital.
\end{abstract}

Results: Of the 27 patients who had received one course of salvage therapy, 13 achieved a complete response and 1 achieved a partial response. We found that the HDAC3-AKT-P21-CDK2 signaling pathway was significantly upregulated in anthracycline-resistant AML cells compared to non-resistant cells. AML patients with higher levels of HDAC3 had lower event-free survival (EFS) and overall survival (OS) rates. Moreover, anthracycline-resistant AML cells are susceptible to chidamide, a histone deacetylase inhibitor which can inhibit cell proliferation, increase cell apoptosis and induce cell-cycle arrest in a time- and dose-dependent manner. Chidamide increases the sensitivity of anthracycline-resistant cells to anthracycline drugs, and these effects are associated with the inhibition of the HDAC3-AKT-P21-CDK2 signaling pathway.

\footnotetext{
*Correspondence: daihongrm@163.com; gaochunji301@163.com;

sliu@umn.edu; lipingruirui@163.com

${ }^{\dagger}$ Hao Wang, Yu-chen Liu and Cheng-ying Zhu contributed equally to this work.

'Department of Hematology, Chinese People's Liberation Army (PLA) General Hospital, 28 Fuxing Road, Beijing 100853, China

${ }^{6}$ The Hormel Institute, University of Minnesota, 801 16th Avenue NE, Austin, MN 55912, USA

Full list of author information is available at the end of the article
}

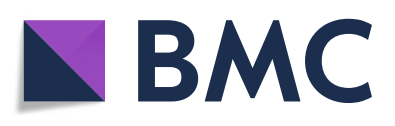

(- The Author(s). 2020 Open Access This article is licensed under a Creative Commons Attribution 4.0 International License, which permits use, sharing, adaptation, distribution and reproduction in any medium or format, as long as you give appropriate credit to the original author(s) and the source, provide a link to the Creative Commons licence, and indicate if changes were made. The images or other third party material in this article are included in the article's Creative Commons licence, unless indicated otherwise in a credit line to the material. If material is not included in the article's Creative Commons licence and your intended use is not permitted by statutory regulation or exceeds the permitted use, you will need to obtain permission directly from the copyright holder. To view a copy of this licence, visit http://creativecommons.org/licenses/by/4.0/. The Creative Commons Public Domain Dedication waiver (http://creativecommons.org/publicdomain/zero/1.0/) applies to the data made available in this article, unless otherwise stated in a credit line to the data. 
(Continued from previous page)

Conclusion: Chidamide can increase anthracycline drug sensitivity by inhibiting HDAC3-AKT-P21-CDK2 signaling pathway, thus demonstrating the potential for application.

Keywords: Chidamide, Histone deacetylase, Histone deacetylase inhibitors, HDAC3, Refractory or relapsed acute myeloid leukemia, PI3K-AKT signaling pathways

\section{Background}

Currently, the treatment for acute myeloid leukemia (AML) includes standard chemotherapy with anthracycline and cytarabine [1, 2]. Although treatment outcomes in adult AML patients have improved over the past decade, up to $30 \%$ of adult patients fail to achieve complete remission (CR) following 2 cycles of intensive chemotherapy. In addition, a large number of patients experienced relapse despite having achieved complete remission [3-5]. Therefore, clinicians continue to find it challenging to manage these two types of patients [6-9]. Furthermore, as the exact mechanism for drug resistance remains largely unclear, there is an urgent need to discover the mechanisms for drug resistance and develop more effective treatment regimens for patients with refractory/relapsed AML.

As a promising class of anticancer drugs, histone deacetylase (HDAC) inhibitors induce apoptosis and suppress tumor cell growth $[10,11]$. Chidamide is a novel oral HDAC inhibitor designed to inhibit the activity of HDAC1, 2, 3 and 10. Chidamide is currently being used in multiple clinical trials as monotherapy or combination therapy for the treatment of various hematological and solid cancers [12-16]. In these trials, chidamide inhibited cell growth in a variety of cancers, such as lung cancer, pancreatic cancer, leukemia, and lymphoma [15-18]. Chidamide has also inhibited the viability of MDS and AML cells [19]. However, the possibility and ways of using chidamide as a treatment option for relapsed/refractory AML following anthracycline therapy remain to be explored. This study shown that chidamide-based regimen improves the overall remision rate of patients with relapsed/refractory AML, as well as prolongs diseasefree survival time and overall survival rates. Moreover, this study is the first to find out chidamide increases the sensitivity of anthracycline-resistant cells to anthracycline drugs, and these effects are associated with the inhibition of the HDAC3-AKT-P21-CDK2 signaling pathway, thus demonstrating the potential for application.

\section{Materials and methods}

\section{Analysis of clinical cases}

Our dataset consists of 27 patients with relapsed/refractory AML, who had received anthracycline-based treatment regimen as induction therapy between Jan. 01, 2018 and Jan. 01, 2019 at the Chinese PLA General Hospital (Supplementary Table 1). According to NCCN (The National Comprehensive Cancer Network) clinical practice guideline for AML, relapse following $\mathrm{CR}$ is defined as the reappearance of leukemic blasts in the peripheral blood or the finding of more than 5\% blasts in the bone marrow, not attributable to any other cause (bone marrow regeneration after consolidation therapy) or extramedullary relapse. Primary refractory or resistant disease is defined by being unable to achieve complete remission after 1 to 2 cycles of intensive induction therapy.

The earliest time at which AML was diagnosed was on Jun. 01, 2016. Patients who relapsed or were resistant to anthracycline were treated with chidamide $(30 \mathrm{mg}$ on days $1,4,8$, and 11) in combination with an anthracycline-based regimen as salvage therapy. The salvage therapy was as follows: (1) chidamide, $30 \mathrm{mg}$, oral, days $1,4,8$, and 11 ; DAC, $20 \mathrm{mg} / \mathrm{m}^{2} /$ d, i.v., days $1-$ 5; Acla, $20 \mathrm{mg} / \mathrm{d}$, i.v., days $1,3,5$; Ara-C, $100 \mathrm{mg} / \mathrm{m}^{2}$, q12h, i.h., days 1-5; G-CSF, $300 \mu \mathrm{g} / \mathrm{d}$, i.h., day 0 until neutrophil levels return to normal. (2) chidamide, $30 \mathrm{mg}$, days 1, 4, 8, and 11; Acla, $20 \mathrm{mg} / \mathrm{d}$, i.v., days 1, 3, 5; AraC, $100 \mathrm{mg} / \mathrm{m}^{2}$, q12h, i.v., days $1-5$; G-CSF, $300 \mu \mathrm{g} / \mathrm{d}$, i.h., day 0 until neutrophil levels return to normal. (3) chidamide, $30 \mathrm{mg}$, days $1,4,8$, and 11 ; mitoxantrone, 5 $\mathrm{mg} /$ d, i.v., days $1-5$; Ara-C, $100 \mathrm{mg} / \mathrm{m}^{2}$, i.h., days $1-5$; VP-16, $100 \mathrm{mg} /$ d, i.v., days 3-5; sorafenib, $400 \mathrm{mg}$, oral, q12h. This study was approved by the ethics committee of the Chinese PLA General Hospital. Patients have given written informed consent for the collection of clinical data.

\section{RNA-sequencing and data analysis}

Total RNA was extracted using TRIzol Reagent (Invitrogen, USA) according to the manufacturer's instructions. RNA-seq was performed with a Genome Analyzer IIx (Illumina, San Diego, CA, USA). Expression levels were measured using the RPKM method, and the distribution of gene expression was analyzed.

\section{TCGA database analysis of HDAC3 prognosis}

AML patient datasets were obtained from The Cancer Genome Atlas database (TCGA) [20], which had integrated clinical and RNA-seq information. Written 
informed consent was obtained from all patients and approved by the Human Studies Committee at Washington University [20]. Patients in the top quartile of HDAC3 expression were classified as high-HDAC3, and patients in the bottom quartile of HDAC3 expression were classified as low-HDAC3.

\section{Drugs and cell lines}

Chidamide was received at no cost from Shenzhen Chipscreen Biosciences Ltd. (Shenzhen, China). K562, K562/A02 (multi-drug resistant leukemic cells, chronic myelogenous leukemia transferred to acute myelogenous leukemia), HL60 and its parallel anthracycline-resistant cell line, HL60/ADR, were kindly gifted by Tianjin Institute of Hematology. The human acute myeloid leukemia were also from Tianjin Institute of Hematology. THP-1 cells were purchased from ATCC (American type culture collection) and THP-1/ADR were its parallel anthracyclineresistant cell line. HEK293T was obtained from ATCC.

The cells were maintained at $37^{\circ} \mathrm{C}$ in a humidified atmosphere containing $5 \% \mathrm{CO}_{2}$. K562/A02 cells were cultured in RPMI-1640 media, supplemented with $10 \%$ fetal bovine serum (FBS), $100 \mu \mathrm{g} / \mathrm{mL}$ penicillin, and $10 \mu \mathrm{g} / \mathrm{mL}$ streptomycin. HEK293T cells were cultured in DMEM with $10 \%$ fetal bovine serum, 2 mM L-glutamine and antibiotics. To maintain drug resistance, doxorubicin was added to the media (final concentration of $0.5 \mu \mathrm{g} / \mathrm{mL}$ ) for at least 1 week every 2 months. One week prior to experiments, cells were re-cultured without doxorubicin [21].

Peripheral blood mononuclear cells (PBMCs) from 22 patients, who had resistance to anthracyclines-based treatment regimens, were isolated with Ficoll-Hypaque centrifugation, and cultured in RPMI-1640 media supplemented with $10 \%$ fetal bovine serum (FBS), $100 \mu \mathrm{g} / \mathrm{mL}$ penicillin, and $10 \mu \mathrm{g} / \mathrm{mL}$ streptomycin. PBMCs were treated with different doses of chidamide as monotherapy or the combination of chidamide + doxorubicin for $24 \mathrm{~h}$ and $48 \mathrm{~h}$, respectively. The basic characteristics are shown in Table 1. All patients have given informed consent for the use of their cells in this study.

\section{Cell proliferation assays}

Cell viability was measured using CCK- 8 assay (Dojindo Molecular Technologies, Inc) according to the manufacturer's instructions. Cells were treated with different concentrations of chidamide as monotherapy or the combination of chidamide + doxorubicin for 24 and 48 h, respectively. Subsequently, $10 \mu \mathrm{L}$ of CCK- 8 was added to each well and incubated for $2-3 \mathrm{~h}$. OD values were measured with a microplate reader at $450 \mathrm{~nm}$.

\section{Cell-cycle analysis}

Following 24 and $48 \mathrm{~h}$, cells were harvested and washed once or twice with PBS and fixed with ethanol overnight. After fixation, the cells were washed with $\mathrm{PBS}$, treated with $100 \mathrm{~g} / \mathrm{mL}$ RNase A, and stained with $100 \mathrm{~g} / \mathrm{mL}$ PI. Cell-cycle data were collected on a flow cytometer with $488 \mathrm{~nm}$ laser and analyzed with MoFlo MLS sorter (Dako, FortCollins, CO).

\section{Apoptosis assays}

At 24 and $48 \mathrm{~h}$ after drug treatment, the cells were harvested, washed twice with ice-cold PBS, and resuspended in binding buffer containing $10 \mathrm{uL}$ PI and $5 \mathrm{uL}$ Annexin-V-FITC (YEASEN) for $15 \mathrm{~min}$ at room temperature in a light-protected chamber. All specimens were analyzed on a FACS Calibur.

\section{Real-time PCR}

Total RNA was extracted by TRIzol (Invitrogen, Carlsbad, CA, USA) and cDNA was synthesized by PrimeScript $^{\text {tix }}$ RT reagent Kit (Takara) according to the manufacturer's instructions. Real-time PCR was then performed using KAPA SYBR FAST q-PCR Master Mix $(2 \mathrm{x})$ Kit using the primers specified in Table 2. We used the 2- $\Delta \Delta \mathrm{Ct}$ formula to examine the relative quantification of the target genes.

\section{Western blot analysis}

After cells were harvested, proteins were separated by SDS polyacrylamide gel electrophoresis (SDS-PAGE)

Table 1 Patients characteristics

\begin{tabular}{llllll}
\hline Number & Diagnosis & Relapse or refractory & sample & Blast & Treatment \\
\hline 1 & AML-M2 & Relapse & PB & $91.2 \%$ & MA, DCAG \\
2 & AML-M2 & Relapse & PB & $87.5 \%$ & CAG, IA, \\
3 & RML-M4 & Relapse & PB & $85.6 \%$ & DCAG, MA \\
4 & AML-M5 & refractory & PB & $98.7 \%$ & DA, DCAG \\
\hline
\end{tabular}

Abbreviations: $P B$ peripheral blood, $M A$ mitoxantrone + cytarabine, $D A$ doxorubicin + cytarabine, $D C A G$ decitabine + aclacinomycin + cytarabine + granulocyte colony stimulating factor, $C A G$ aclacinomycin + cytarabine + granulocyte-colony stimulating factor; 
Table 2 Primers sequences $\left(5^{\prime}-3^{\prime}\right)$

\begin{tabular}{lll}
\hline Gene & Forward primers sequences & Reverse primers sequences \\
\hline HDAC1 & AACTgCTAAAgTATCACCAgAggg & TggCCTCATAggACTCgTCA \\
HDAC2 & TCCTgAggTggTTggTggC & ATATCACCgTCgTAgTAgTAgCAgA \\
HDAC3 & ATgCCTTCAACgTAggCgATg & CgAgggTggTACTTgAgCAgC \\
HDAC10 & TCggCAggATTgACTCAgC & TggACTCTAgggCACTCTgAC \\
AKT & AAgTCATCgTggCCAAggAC & AggTggAAgACAgCTCgC \\
P21 & gAgCTgCgCCAgCTgAggTgT & gACATggCgCCTCCTCTgAgTgCC \\
CDK2 & TggACACgCTgCTggATg & AATggCAgAAAgCTAggCCC \\
GAPDH & CTCTggTAAATTgATATTIT & ggTggAATCATATTggACA \\
\hline
\end{tabular}

and transferred onto a polyvinylidene difluoride membrane. The blots were blocked with $5 \%$ non-fat dry milk at $37^{\circ} \mathrm{C}$ for $2 \mathrm{~h}$ and incubated with a specific primary antibody and secondary antibody according to the manufacturer's instructions.

\section{HDAC activity assay}

HDAC activity was detected using a Colorimetric HDAC Activity Assay Kit (BioVision). Each reaction was conducted with $100 \mu \mathrm{L}$, which contained $50 \mu \mathrm{g}$ of proteins extracted from cells. HDAC activity was measured with a microplate reader (SpectramMaxM5) at $405 \mathrm{~nm}$.

\section{Plasmid and transfection}

HDAC3 shRNA plasmid (sc-35,538-SH, Santa Cruz Biotechnology, City, State, Country) was transfected into cells using Superfect reagent (Qiagen) according to the manufacturer's protocol. Transfected cells with nonspecific shRNA plasmid were used as blank control. HAHDAC3 plasmid (NM_003883-HA) and its corresponding control plasmid were obtain from Genechem. FlagAKT and its control plasmid were purchase from Hanbio. Plasmids and their respective control were transfected into cells using Lipofectamine ${ }^{\mathrm{Tm}} 3000$ reagent (ThermoFisher \#L3000008). After transfection, cells were subjected to RT-PCR and Western blot to verify HDAC3 or ATK expression.

\section{Co-immunoprecipitation}

HEK293 cells were transfected with Flag-AKT (wild type) alone or plus HA-HDAC3 for $48 \mathrm{~h}$. And lysates immunoprecipitated with Flag were immunoblotted for Acetylated-lysine, HA, p-AKT and Flag. Coimmunoprecipitation reagents (ThermoFisher, \#88804) were obtain from ThermoFisher.

\section{In vivo study}

The xenograft experiments were performed in NOD/ SCID immunodeficient mice (aged 6-8 weeks). The mice were maintained in an air-conditioned pathogen-free room under conditions of controlled lighting (12 h light and $12 \mathrm{~h}$ dark per day) and fed a standard diet of laboratory rodent food and water. $1 * 10^{7}$ cells K562/A02 cells in $200 \mu \mathrm{L}$ PBS were injected subcutaneously into the lateral flanks of mice. Tumors were observed and measured every other day. The tumor volumes were determined by the formula $\mathrm{V}=0.5^{*}$ Length $^{*}$ width $^{2}$. The tumor-bearing mice were randomized into 4 groups $(n=5$, Figure S3A). The mice in doxorubicin-treated group were injected doxorubicin at the dose of $5 \mathrm{mg} / \mathrm{kg}$ intraperitoneally once a week and intragastrically instillated normal saline at the same time. The mice in chidamide-treated group were intragastrically instillated at the dose of $5 \mathrm{mg} / \mathrm{kg}$ chidamide three times a week and injected with PBS. And the mice in group control were treated both with PBS and normal saline as a control. The mice in the combined-therapy treated group received both intraperitoneal injection of doxorubicin and intragastric instillation of chidamide. Mice were sacrificed at the 21st day after inoculation and tumors were harvested for molecular characterizations. All animal experiments complied with the international and institutional rules and all animal protocols were approved by the Experimental Animal Ethics Committee of Chinese PLA General Hospital.

\section{Statistical analysis}

To determine gene expressions, the threshold of q-value was set at 0.05 , and the absolute value of $\log _{2}$ ratios at KEGG and GO enrichment using the database for Annotation. Modified Fisher's exact test was used to analyze the significance of GO and KEGG enrichment. Data obtained from triplicated experiments were reported in mean \pm SD and analyzed using SPSS18.0 software. An appropriate Mann-Whitney test or Student's t-test was adopted to perform comparisons. Kaplan-Meier method and log-rank test were used to analyze the relationship between HDAC3 expression levels and OS or EFS. Cox proportional hazard models were performed to test the associations between HDAC3 expression levels, OS and EFS using multivariate analysis. All data were analyzed using the R 3.1.1 software, 
and $P$-values below 0.05 were considered to be statistically significant. (" $P<0.05$, ${ }^{* * *} P<0.01$, **** $\left.P<0.001\right)$.

\section{Results \\ Combination of chidamide with anthracycline-based treatment for R/R AML patients}

To test the effects of the combination of chidamide and anthracycline in vivo, twenty-seven patients with $R / R$ AML received the combination therapy of chidamide and anthracycline-based treatment regimen between Jan.01, 2018 and Jan. 01, 2019 at the Chinese PLA General Hospital. Patient characteristics are presented in Table 3. Thirteen were female and fourteen were male, and the median age was 51 (range, 12-71) years. Ten (37.04\%) patients had relapsed AML and seventeen (62.96\%) patients had refractory AML. Pre-treatment levels of median marrow blasts, white blood cells, hemoglobin, and platelets were 27.6 (2.50-97.0)\%, 3.95 $(1.40-49.13) \times 10 / \mathrm{L}, 96(71-120) \mathrm{g} / \mathrm{L}$, and $101 \quad(16-$ 226) $\times 10^{9} / \mathrm{L}$, respectively. Among 27 patients, 3 patients had FLT3-ITD mutation, 3 patients had DNMT3A mutation, 1 patient had BCOR mutation, 2 patients had NRAS mutation, and 1 patient had STAG2 mutation. Nine patients had documented poor-risk cytogenetics, as defined by the NCCN guidelines for AML.

Of the 27 patients who had received one course of salvage therapy, 13 achieved a complete response and 1 achieved a partial response. OS rates for 1 and 3 years were $50.44 \%$ (95\% CI, 34.47-73.81\%) and 28.29\% (95\% CI, 14.68-54.52\%), respectively (Fig. 1a). Progressionfree survival (PFS) rates for 6 months and 1 year were 51.36\% (95\% CI, 35.46-74.38\%) and 34.24\% (95\% CI, 19.85-59.06\%), respectively (Fig. 1B). Following salvage therapy with a combination of chidamide and anthracycline-based regimen, 26 patients showed grade IV bone marrow suppression, and 1 patient showed grade III bone marrow suppression. The lowest WBC was $0.49(0.02-1.08) \times 10^{9} / \mathrm{L}$ and the lowest platelet count was $17(2-45) \times 10^{9} / \mathrm{L}$. The duration of IV suppression was 8 (2-28) days for leukocytes and 8 (219) days for platelets. During the treatment, 1 patient reported a new case of pulmonary fungal infection and 2 patients experienced skin infections. Other adverse events include diarrhea, grade I drug-induced liver damage, cholecystitis, and sepsis, with 1 patient reporting each of the events.

\section{The HDAC3-AKT-P21-CDK2 cell signaling pathway is activated in anthracycline-resistant cells compared to non-resistant cells}

HL60, THP-1 and K562 are doxorubicin sensitive cell lines, while HL60/ADR, THP-1/ADR and K562/A02 cells are doxorubicin nonsensitive cell lines. In order to verify the characteristics of drug resistance, we exposed
HL60 and HL60/ADR cells to different concentrations of doxorubicin for $24 \mathrm{~h}$, examined the inhibitory activities of doxorubicin on both cell lines by using CCK-8 method. THP-1, K562 and its parallel anthracycline-resistant THP-1/ADR or K562/A02 cells were treated in the same way. As shown in (Supplemental Figure 1A-1B), doxorubin showed different activity in inhibition proliferation of HL60/ADR and HL60 cells, with the IC50 to be $4.818 \mu \mathrm{g} / \mathrm{ml}$ and $0.194 \mu \mathrm{g} / \mathrm{ml}$, respectively. Compared with HL60 cell, HL60/ADR has 25.4 fold resistance to doxorubin. The IC50 of $\mathrm{K} 562$ and $\mathrm{K} 562 / \mathrm{A} 02$ were $0.79 \mu \mathrm{g} / \mathrm{ml}$ and $25.462 \mu \mathrm{g} / \mathrm{ml}$. Compared with K562 cell, K562/A02 has 32.2 fold resistance to doxorubin (Figure S1C-D). Compared with THP-1 cell, THP-1/ADR has 29.4 fold resistance to doxorubin (Figure S1E-F). These results suggested that HL60/ADR, THP-1/ADR and K562/A02 had the characteristics of doxorubin drug resistance.

This study shown that the chidamide-based regimen improves the overall remision rate of patients with relapsed/refractory AML, so we want to further analyze the mechanism of bring such good clinical therapeutic results.

To study the mechanism of drug resistance in leukemia cells, we performed RNA sequencing (RNAseq) on K562 cells and K562/A02 (doxorubicin-resistant leukemia) cells. As shown in the Volcano plot (Fig. 2a), RNA-seq identified 368 up-regulated and 171 downregulated genes in K562/A02 cells. The HDAC3 gene was shown to be one of the highly expressed genes in K562/A02, as compared to that in K562 cells. Drug resistance was closely associated with different cell signaling pathways (with reference to literature), while the PI3K-AKT cell signaling pathway was significantly different between K562 and K562/A02 (Fig. 2b). Within the PI3K-AKT cell signaling pathways, the up-regulated genes were AKT, CDK2, but P21 expression was not significantly different. To further verify the RNA-seq results, we compared the differential gene expression between HL60/ADR and HL60, K562/A02 and K562 cells using quantitative PCR. The expressions of HDAC3, AKT and CDK2 genes were higher in HL60/ ADR (Fig. 2c) and in K562/A02 (Figure S2A), while the expression of P21 significantly decreased (Fig. 2c; Figure S2A). These results supported the RNA-seq results. It was previously reported that HDACs can affect the proliferation of malignant tumor cells by altering the expression of oncogenes or tumor suppressor genes [22]. Moreover, aberrant expression of HDACs may protect cells from genotoxic insults [23]. Therefore, we examined whether the HDAC1, HDAC2, and HDAC10 genes were also differentially expressed. However, we did not find significant changes in their expression levels (Fig. 2c, d; Figure S2A, S2B). 
Table 3 Patients characteristics

\begin{tabular}{|c|c|c|}
\hline Characteristics & $\mathbf{N}$ & $\%$ \\
\hline Patient age, median (range) & $51(12-71)$ & \\
\hline \multicolumn{3}{|l|}{ Patient gender } \\
\hline Male & 14 & 51.85 \\
\hline Female & 13 & 48.15 \\
\hline Relapse & 10 & 37.04 \\
\hline Refractory & 17 & 62.96 \\
\hline \multicolumn{3}{|l|}{ Diagnosis (WHO) } \\
\hline M1 & 0 & 0 \\
\hline M2 & 4 & 14.81 \\
\hline M4 & 8 & 29.63 \\
\hline M5 & 12 & 44.44 \\
\hline M6 & 2 & 7.41 \\
\hline unavailable & 1 & 3.71 \\
\hline $\mathrm{Hb}, \times g / L$ median (range) & $96(71-120)$ & \\
\hline $\mathrm{WBC}, \times 10^{9} / \mathrm{L}$ median (range) & $3.95(1.40-49.13)$ & \\
\hline Platelets, $\times 10^{9} / \mathrm{L}$ median (range) & $101(16-226)$ & \\
\hline BM blasts median (range) & $27.6(2.50-97.0)$ & \\
\hline \multicolumn{3}{|l|}{ karyotype-risk $(n=)^{a}$} \\
\hline Favorable-risk & 7 & 25.93 \\
\hline Intermediate-risk & 1 & 3.70 \\
\hline Poor-risk & 9 & 33.33 \\
\hline Unavailable & 10 & 37.04 \\
\hline \multicolumn{3}{|l|}{ DNMT3A mutational status } \\
\hline Wild-type DNMT3A & 18 & 66.67 \\
\hline DNMT3Amutation & 3 & 11.11 \\
\hline Missing & 6 & 22.22 \\
\hline \multicolumn{3}{|l|}{ TP53 mutational status } \\
\hline Wild-type TP53 & 19 & 70.37 \\
\hline TP53 mutation & 2 & 7.41 \\
\hline Missing & 6 & 22.22 \\
\hline \multicolumn{3}{|l|}{ FLT3-ITD mutational status } \\
\hline Wild-type FLT3-ITD & 18 & 66.67 \\
\hline FLT3-ITD mutation & 3 & 11.11 \\
\hline Missing & 6 & 22.22 \\
\hline \multicolumn{3}{|l|}{ BCOR mutational status } \\
\hline Wild-type BCOR & 20 & 74.08 \\
\hline BCOR mutation & 1 & 3.70 \\
\hline Missing & 6 & 22.22 \\
\hline \multicolumn{3}{|l|}{ NRAS mutational status } \\
\hline Wild-type NRAS & 19 & 70.37 \\
\hline NRAS mutation & 2 & 7.41 \\
\hline Missing & 6 & 22.22 \\
\hline
\end{tabular}

Table 3 Patients characteristics (Continued)

\begin{tabular}{|c|c|c|}
\hline Characteristics & $\mathrm{N}$ & $\%$ \\
\hline \multicolumn{3}{|c|}{ STAG2 mutational status } \\
\hline Wild-type STAG2 & 20 & 74.08 \\
\hline STAG2 mutation & 1 & 3.70 \\
\hline Missing & 6 & 22.22 \\
\hline \multicolumn{3}{|c|}{$\begin{array}{l}\text { Abbreviations: } B M \text { bone marrow, } W B C \text { white blood count, } H B \text { hemoglobin, } \\
P L T \text { Platelet } \\
{ }^{a} \text { Cytogenetic groups were defined as follows: favourable }-\mathrm{t}(8 ; 21) \text {, inv. (16), } \\
\text { irrespective of the presence of other abnormalities; adverse - monosomy5, } \\
\text { monosomy } 7 \text {, del( } 5 q) \text {, abnormal } 3 q \text {, complex ( } 5 \text { or more chromosomal } \\
\text { abnormalities); intermediate - all other abnormal karyotypes, } \\
\text { normal karyotype }\end{array}$} \\
\hline
\end{tabular}

To determine whether proteins within the HDAC3AKT-P21-CDK2 signaling network were differentially regulated, we examined the expression of HDAC3, P-AKT and CDK2 in HL60/ADR and K562/A02 cells. The expression of HDAC3, P-AKT and CDK2 proteins was higher in HL60/ADR (Fig. 2d) and K562/A02 (Fig. S2B), while that of P21 and AKT protein was similar in HL60 and HL60/ADR cells, K562 and K562/A02 cells (Fig. 2d; Figure S2B). Given the close relationship between HDAC3 and AKT [24, 25], our results, which showed that HDAC3 and $\mathrm{P}$-AKT are positively correlated, support the idea that the activation of HDAC3-AKT-P21-CDK2 signal pathways may contribute to anthracycline resistance. This study is the first to find out HDAC3-AKT-P21-CDK2 signal pathways is related to anthracycline resistance .

\section{High expression levels of HDAC3 are associated with poorer prognoses}

The above results suggest that high expression levels of HDAC3 were related to anthracycline resistance. HDAC3 expression of primary leukemia cells from 17 AML patients (de novo samples and relapsed samples) were detected by q-PCR. The expression of HDAC3 in relapsed patients was significantly higher than that in de novo counterparts (Fig. 2e). Interestingly, the expression level of HDAC3 in the relapsed samples from the same patient was higher than that in his de novo samples (Fig. 2f). The qPCR results of the patients showed that the expression of HDAC3 was significantly higher in anthracicycline-resistant cells.

Then we examined whether high expression levels of HDAC3 are associated with poorer prognoses. We analyzed a cohort of 163 patients with de novo AML from the TCGA dataset. These patients were divided into $\mathrm{HDAC}^{\text {Low }}$ and HDAC3 ${ }^{\text {High }}$ groups according to their expression levels of HDAC3. This analysis showed that patients with $\mathrm{HDAC} 3^{\text {High }}$ had lower median OS (Fig. 3a) and EFS time (Fig. $3 \mathrm{~b}$ ). We also performed multivariate Cox proportional hazard models to analyze the prognosis of HDAC3 expression. In the multivariate analyses, 
A

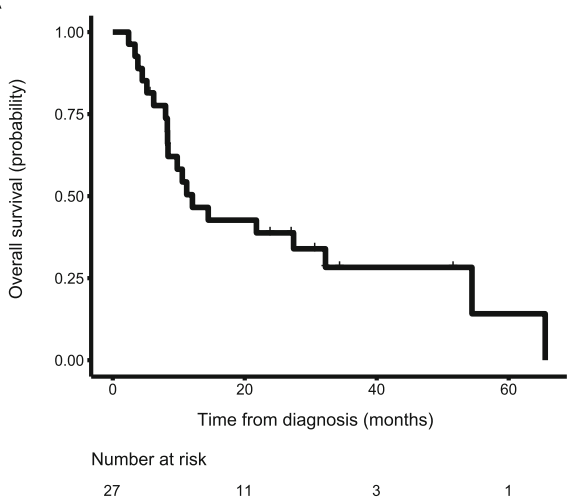

B

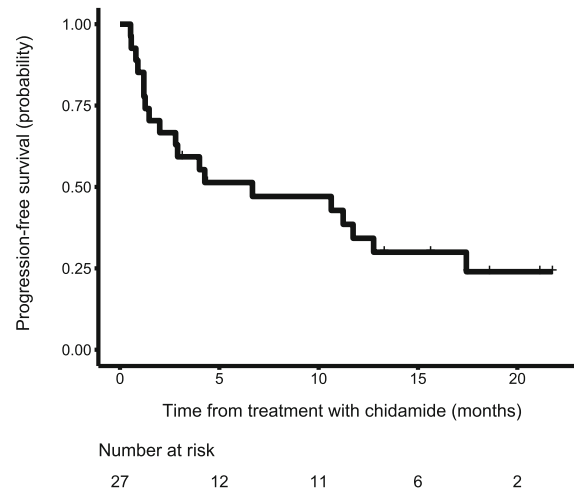

Fig. 1 Kaplan-Meier estimates of survival rates of R/R AML (acute myeloid leukemia) patients following combination therapy of chidamide and anthracycline-based regimen. a OS. b Progression-free survival

HDAC $3^{\text {High }}$ expression had an adverse impact on OS (Fig. 3c) and EFS (Fig. 3d).

\section{Chidamide synergizes with anthracycline drugs which potently inhibited tumor growth and suppressed HDAC3- AKT-P21-CDK2 signaling pathway in vivo}

To further validate the combination effect of chidamide with doxorubicin in vivo, we established a xenograft mouse model by subcutaneously inoculating K562/ADR cells into NOD/SCID mice (total $=20)$. The mice were randomized into 4 groups $(n=5)$. And the mice in the doxorubicin-treated group were injected doxorubicin at the dose of $5 \mathrm{mg} / \mathrm{kg}$ intraperitoneally once a week and intragastrically instillated normal saline at the same time. The mice in the chidamide-treated group were intragastrically instillated at the dose of $5 \mathrm{mg} / \mathrm{kg}$ chidamide three times a week and injected with PBS at the same time. And the mice in group control were treated both with PBS and normal saline as a control. The mice in the combined-therapy group received both intraperitoneal injection of doxorubicin and intragastric instillation of chidamide (Figure S3A). The volume of tumors in the control group and only doxorubicin treated group was larger than that of tumors in the combination group (Figure S3B). The tumor volumes and the tumor weights at the terminal point were extremely smaller in the combined group than in the control and doxorubicin groups (Figure S3C-E). Moreover, the mRNA expression of HDAC3, AKT, CDK2 decreased and P21 increased in chidamide treated group (Figure S3F). These results indicated that chidamide combined with doxorubicin could significantly inhibit tumor growth.

Chidamide potently inhibits the viability of anthracyclineresistant AML cells

To determine whether chidamide inhibits anthracyclineresistant AML cell growth, cell viability was determined using the CCK-8 assays. HL60/ADR cells, K562/A02 cells and THP-1/ADR cells were treated with $0,0.5,1$, or $2 \mu \mathrm{M}$ chidamide for $24 \mathrm{~h}$ or $48 \mathrm{~h}$. As shown in Fig. $4 \mathrm{a}$, $\mathrm{b}$ and Figure S4A, chidamide suppressed HL60/ADR cells, K562/A02 cells and THP-1/ADR cells proliferation in a time-dependent manner. And cell viability probability was $43.7 \% \pm 2.0 \%$ (HL60/ADR), $42.8 \% \pm 1.4 \%$ (K562/ A02) and $35.45 \% \pm 1.69 \%$ (THP-1/ADR) at a concentration of $2 \mu \mathrm{M}$ for $48 \mathrm{~h}$. Consistently, when patient-derived $\mathrm{R} / \mathrm{R}$ AML cells were treated with $0,0.3,0.5,1 \mu \mathrm{M}$ for 24 $\mathrm{h}$ or $48 \mathrm{~h}$, chidamide exhibited potent inhibition in patient-derived anthracycline-resistant AML blasts, especially at $48 \mathrm{~h}$ after $1 \mu \mathrm{M}$ chidamide treatment, which reduced viability to $61.6 \pm 6.1 \%$ (Fig. 4c). These results suggest that chidamide inhibits the proliferation of anthracycline-resistant AML cells in a dose- and timedependent manner.

To study whether chidamide induces cell-cycle arrest in resistant AML cells, HL60/ADR cells, K562/ A02 and THP-1/ADR cells were treated with 0, 0.01, $0.05,0.1 \mu \mathrm{M}$ for $24 \mathrm{~h}$ or $48 \mathrm{~h}$, respectively. Flow cytometry was used to measure changes in the cell cycle. Chidamide increased the percentage of cells in G0/G1 phase in a dose- and time-dependent manner (Fig. 4d; Figure S4B; Figure S4D). The percentage of cells in S phase decreased in a dose- and time-dependent manner (Fig. 4e; Figure S4C; Figure S4E).

To determine the apoptotic effect of chidamide on anthracycline-resistant AML cells, HL60/ADR cells, K562/A02 and THP-1/ADR cells were treated with 0 , $0.01,0.05,0.1 \mu \mathrm{M}$ for $24 \mathrm{~h}$ or $48 \mathrm{~h}$, respectively, and double-stained with Annexin V/PI before being analyzed using flow cytometry. As shown in Fig. 4f-g, Figure S4F$\mathrm{G}$ and Figure S4H-I, chidamide significantly increased apoptotic cells in comparison to control cells. The proportion of apoptotic cells continued to increase following chidamide treatment. These findings suggest that 


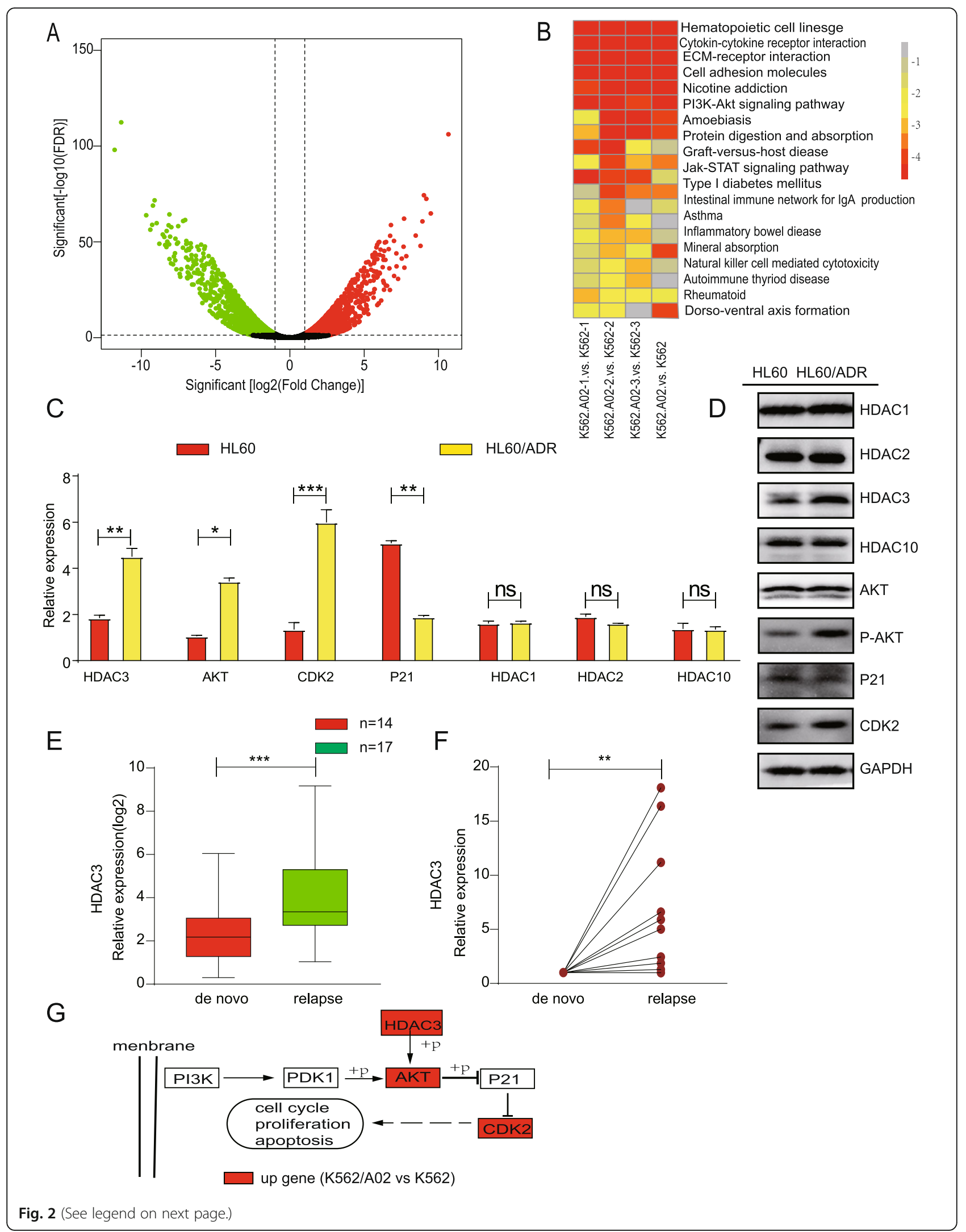


(See figure on previous page.)

Fig. 2 Differential gene and protein expression in K562 and K562/A02. a Total RNA isolated from K562 and K562/A02 was subjected to RNAsequencing. The Volcano plot of differentially expressed gene level was defined by analysis of variance. $\mathbf{b}$ KEGG pathway analyes of differentially expressed genes. c RT-PCR analysis showed differential gene expression in HL60 and HL60/ADR. $\mathbf{d}$ Western blot analysis shows protein expression of differential gene in HL60 and HL60/ADR. e HDAC3 expression of relapsed patients measured with RT-PCR was compared to that of de novo counterparts. $\mathbf{f}$ The HDAC3 expression of relapsed samples from the same patients measured with RT-PCR was compared to that of its de novo leukemia samples. g Compared with K562 cells, the HDAC3-AKT-P21-CDK2 signaling pathway was activated in K562/A02 cells (red represents higher expression). Data represents three independent experiments, and results shown are in the format, mean \pm S.D. (NS: $P>0.05,{ }^{*} P<0.05$, $\left.{ }^{*} P<0.01,{ }^{* * *} P<0.001\right)$

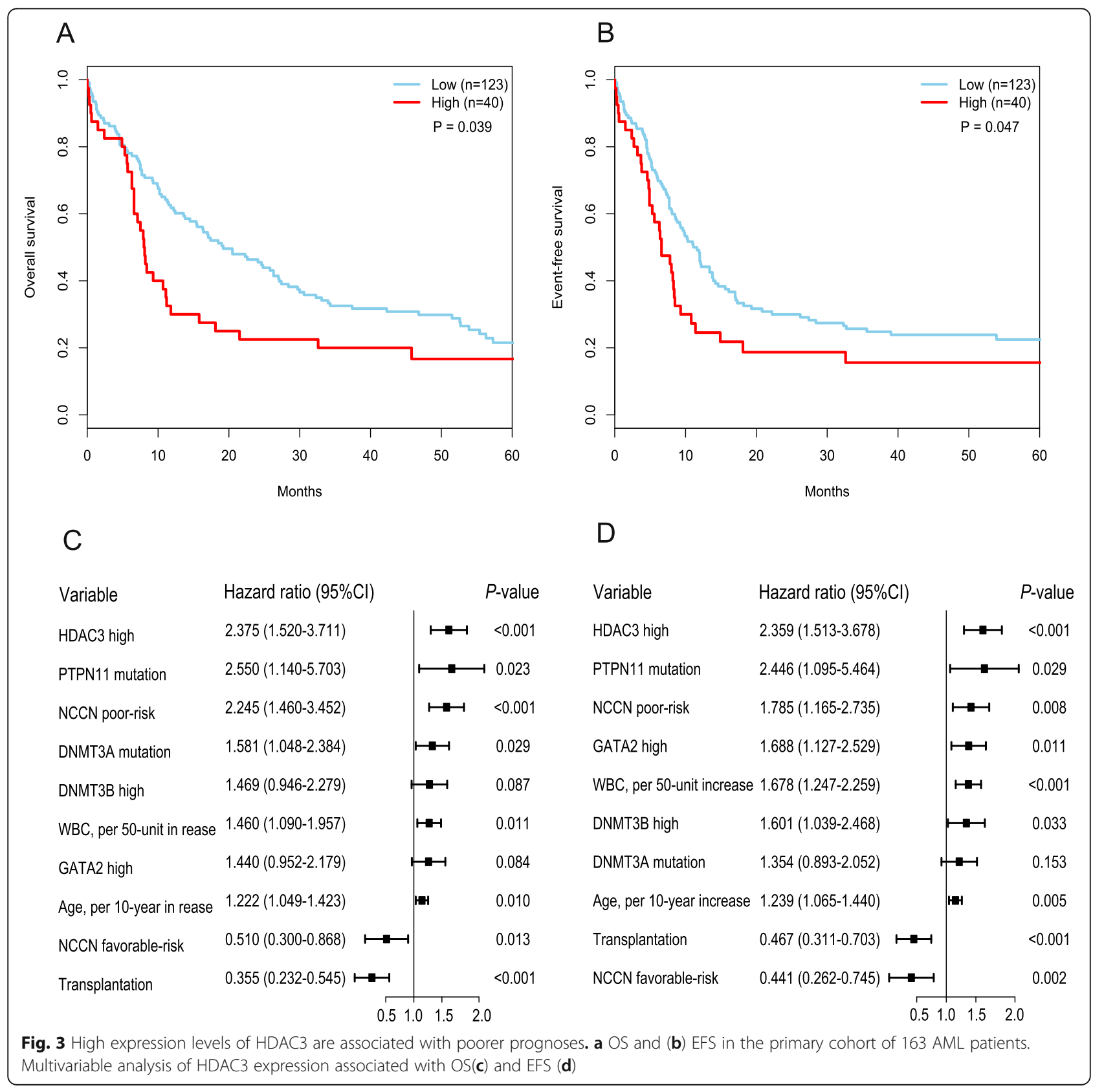




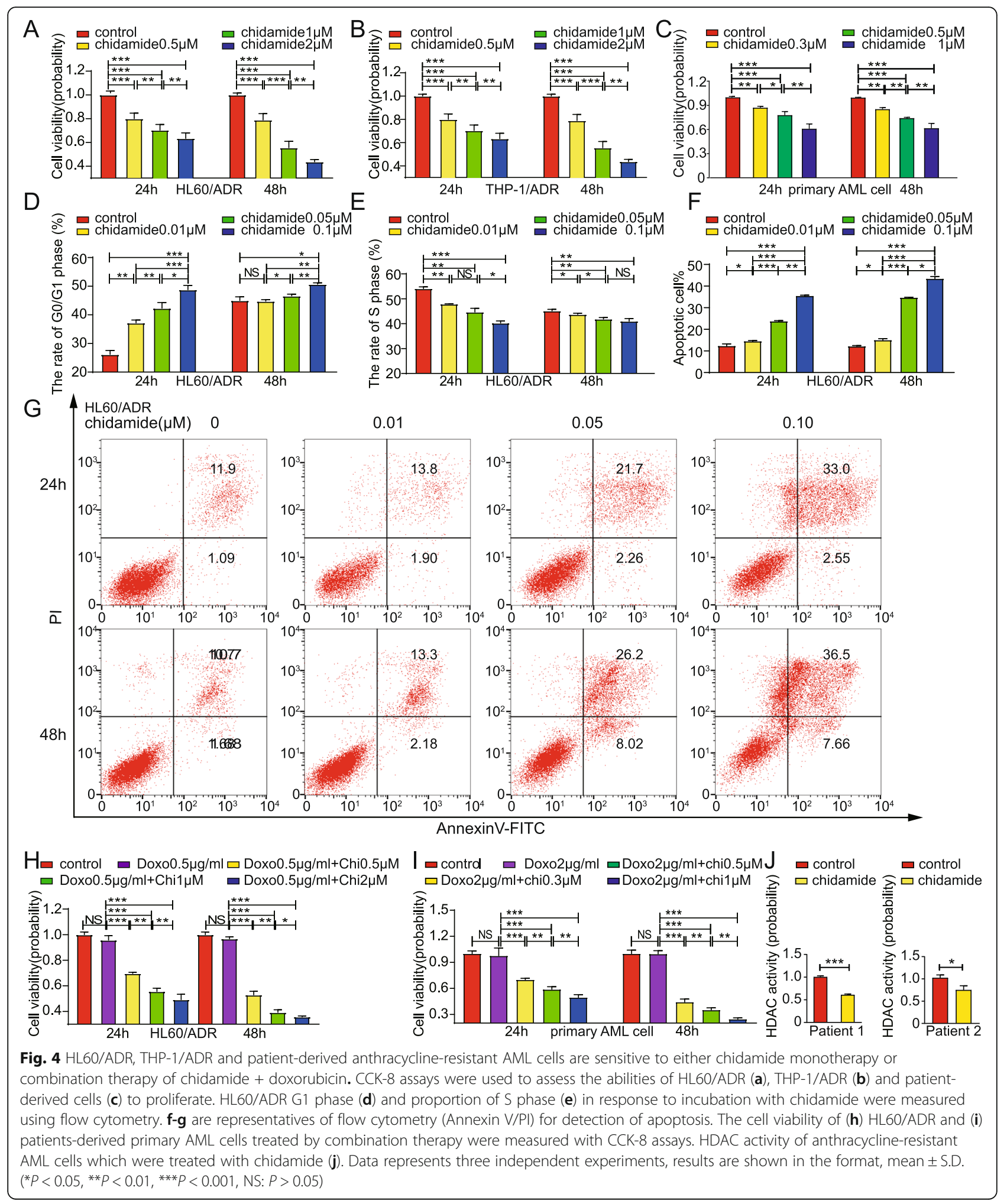

chidamide induces apoptosis in resistant AML cells in a concentration- and time-dependent manner.

To determine the effect of chidamide on anthracycline-sensitive AML cells, the experiments were performed in anthracycline-sensitive HL60, K562 and patient-derived AML cells. CCK-8 assays showed that chidamide inhibited the anthracycline-sensitive AML cell growth. K562 cells, HL60 cells and anthracycline- 
sensitive primary AML cells, as shown in Figure S4J-L. Cell viability was reduced to $86.5 \pm 5.2 \%$ (K562, Figure S4J), $82.5 \pm 2.7 \%$ (HL60, Figure S4K) and $88.3 \pm 6.6 \%$ (primary AML cell, Figure S4L) at a concentration of $0.5 \mu \mathrm{M}$ for $24 \mathrm{~h}$, and $65.8 \pm 2.8 \%(\mathrm{~K} 562$, Figure S4J), $63.5 \pm 1.8 \%$ (HL60, Figure S4K) and $59.1 \pm 12.1 \%$ (primary AML cell, Figure S4L) for $48 \mathrm{~h}$. Chidamide significantly increased apoptotic cells in comparison to control cells both in K562 cells and HL60 cells (Figure S4M-P), suggesting that chidamide also induced apoptosis in sensitive AML cells. Cell cycle study showed that chidamide increased the rate of cells in G0/G1 phase, while decreased the rate of cells in $\mathrm{S}$ phase (Figure S4Q-T). These results demonstrate that chidamide also inhibits the cell viability of anthracycline-sensitive AML cells.

\section{Combination of chidamide and doxorubicin potently} impairs the viability of anthracycline-resistant AML cells

Next, we sought to determine whether chidamide sensitizes anthracycline-resistant AML cells to doxorubicin treatment. As shown in Fig. 4h, i, Figure S4U, and Figure $\mathrm{S} 4 \mathrm{~V}$ the combination of chidamide and doxorubicin exhibited greater inhibition on the growth of HL60/ADR, K562/A02, THP-1/ADR and patient-derived anthracycline-resistant AML cells, as compared to doxorubicin monotherapy. Inhibitory effects of the combination therapy were significantly greater at $48 \mathrm{~h}$. These data indicate that the inhibitory effects of doxorubicin were significantly enhanced by chidamide in a dose- and time-dependent manner. Therefore, the combination of chidamide and doxorubicin had a pronounced inhibition effect on anthracycline-resistant AML cells.

\section{Chidamide inhibits HDAC activity in anthracycline- resistant leukemia cells}

To test the activity and efficacy of chidamide in anthracycline-resistant AML cells, K562/A02, and patient-derived anthracycline-resistant AML cells were treated with chidamide for $48 \mathrm{~h}$. An HDAC activity assay was used to measure HDAC activity. As shown in Fig. 4j, Figure S4W, HDAC activity was inhibited by chidamide.

\section{Chidamide suppresses HDAC3-Akt-P21-CDK2 signaling pathways}

Having shown that HDAC3-AKT-P21-CDK2 signaling pathways were activated in anthracycline-resistant AML cells, we sought to examine whether resistance reversal by chidamide occurs through the HDAC3-AKT-P21CDK2 signaling pathway. Effects of different doses of chidamide on the HDAC3-AKT-P21-CDK2 pathway were determined by measuring mRNA expression levels in anthracycline-resistant cells. In comparison to control cells of HL60/ADR (Fig. 5a), K562/A02 (Figure S5A) and THP-1/ADR (Figure S5B), chidamide monotherapy led to significant inhibition of the expression of HDAC3, $\mathrm{AKT}$, and CDK2, and increased P21 expression in a dose-dependent manner. Similarly, we treated patientderived anthracycline-resistant AML cells with $0.3 \mu \mathrm{M}$ chidamide and found that the expression levels of HDAC3, AKT, and CDK2 decreased while P21 expression increased, compared to control cells (Fig. 5b and c). Furthermore, chidamide inhibited HDAC3, P-AKT, and CDK2 protein expression significantly, but increased P21 protein expression in a dose-dependent manner, while no significant changes in AKT protein levels were observed in HL60/ADR cells, K562/A02 cells, THP-1/ADR and primary AML cells (Fig. $5 \mathrm{~d}$, e; Figure S5C-D).

Lastly, HL60/ADR cells, K562/A02 cells, THP-1/ADR and primary AML cells were exposed to a combination of doxorubicin and different doses of chidamide. The results showed that the combination of chidamide and doxorubicin downregulated HDAC3, AKT, and CDK2 expression significantly, while increasing the mRNA levels of P21 in a dose-dependent manner in these anthracycline-resistant cells (Fig. 5f, h; Figure S5E; Figure S5G). Moreover, combination therapy for HL60/ ADR cells, K562/A02 cells, THP-1/ADR and primary AML cells decreased HDAC3, P-AKT, CDK2 protein expression, but increased $\mathrm{P} 21$ protein expression in a dose-dependent manner (Fig. 5g, i; Figure S5F; Figure S5H). Again, AKT protein levels remained unchanged. These results demonstrate that chidamide monotherapy or the combination therapy of chidamide and doxorubicin are able to suppress the HDAC3-AKT-P21-CDK2 signaling pathway.

HDAC3 silencing reduces cell proliferation, increases cell apoptosis, induces cell cycle arrest at G0/G1 phase, and suppresses the levels of AKT, P21, and CDK2

To examine the effects of HDAC3 silencing on the viability of HL60/ADR cells and K562/A02 cells, HL60/ADR cells and K562/A02 cells were transfected with HDAC3 shRNA. CCK-8 assays showed that cell proliferation was significantly suppressed by $71.08 \pm 1.92 \%$ (HL60/ADR cells), $50.5 \pm 2.6 \%$ (K562/ A02 cells) in HDAC3 shRNA knockdown cells (Fig. 6a; Figure S6A). The proportion of apoptotic cells was greater in cells with HDAC3 knockdown compared to control cells (Fig. 6b-c; Figure S6B-C). Moreover, HDAC3 silencing reduced the proportion of cells in the $S$ phase and induced cell cycle arrest in G0/G1 phase (Fig. 6d-f; Figure S6D-F).

Next, we analyzed the effect of HDAC3 silencing on AKT-P21-CDK2 signal axis by qRT-PCR and Western blot. As anticipated, transfection with HDAC3 shRNA 


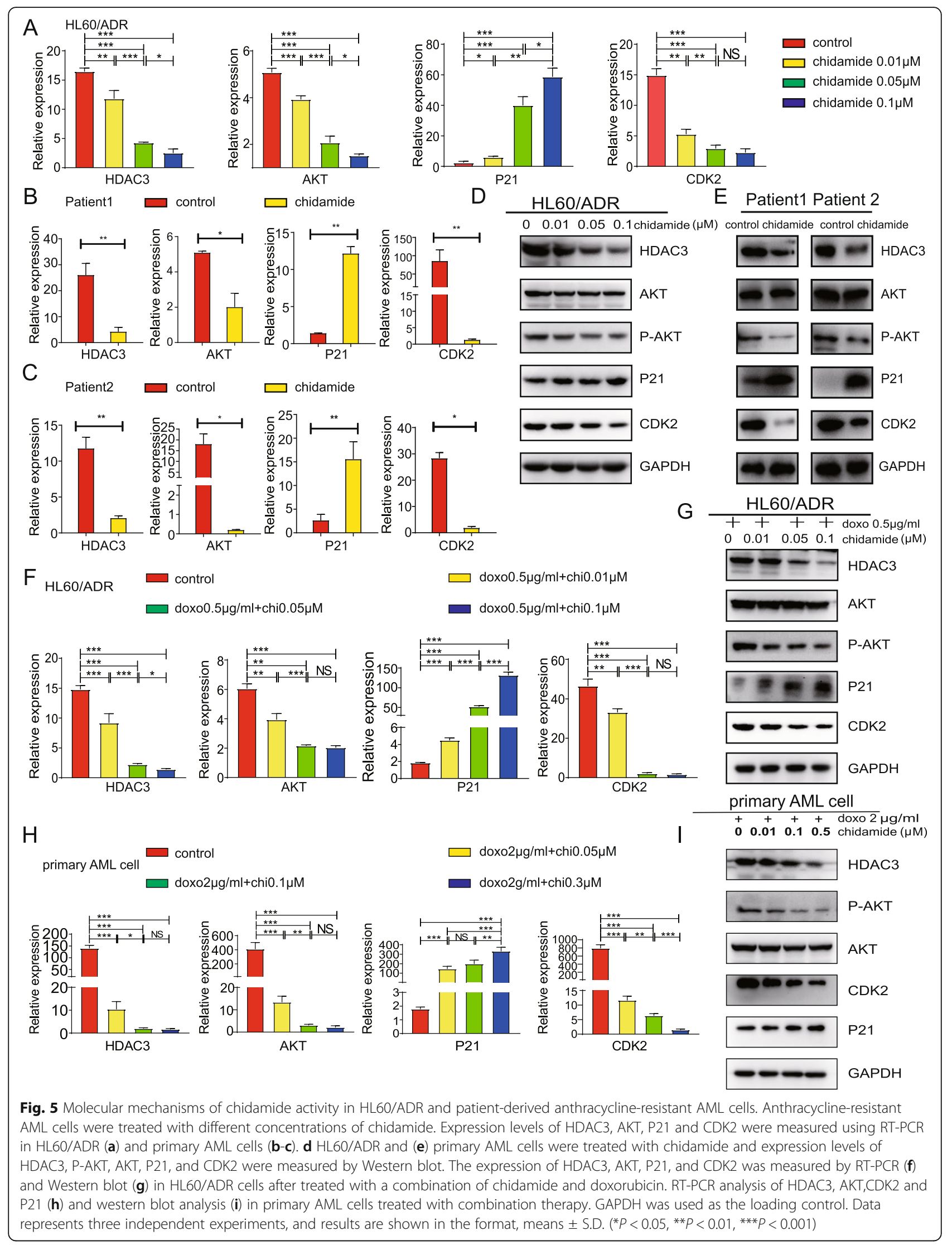




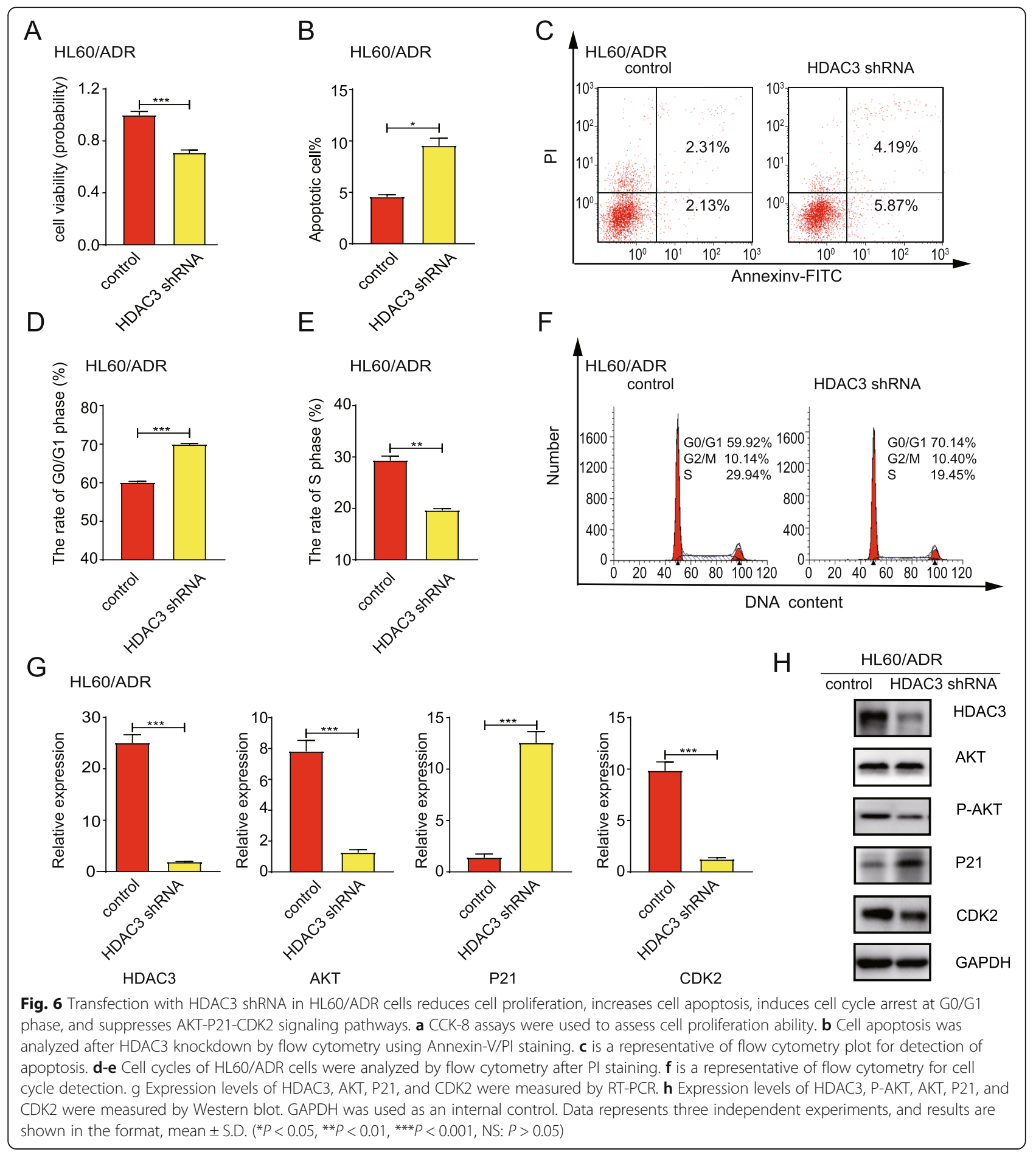

resulted in a decrease in HDAC3, AKT, and CDK2 expression, but an increase in mRNA and protein levels of P21 (Fig. 6g-h; Figure S6G-H). These results further support the hypothesis that HDAC3 regulates the activity of AKT. Inhibiting HDAC3 expression decreases the expression of P-AKT and inactivates the AKT-P21CDK2 signal axis.
AKT inhibitor reduces cell proliferation, increases cell apoptosis, induces cell cycle arrest at G0/G1 phase, and suppresses CDK2-P21 signaling pathways

To determine the role of AKT in drug resistance, HL60/ ADR cells and K562/A02 cells were exposed to MK2206-HCL, an AKT inhibitor. CCK-8 assays revealed that MK2206-HCL treatment significantly reduced cell 
proliferation to $66.04 \pm 0.63 \%$ (HL60/ADR cells, Fig. 7a), $29.0 \pm 11.3 \%$ (K562/A02 cells, Figure S7A). Moreover, AKT inhibition led to a higher ratio of apoptotic cells (Fig. 7b-c; Figure S7B-C), a reduction of cell proportion in $\mathrm{S}$ phase, as well as an induction of cell cycle arrest at the G0/G1 phase (Fig. 7d-f; Figure S7D-F). Taking the mechanisms into account, treatment with AKT inhibitor resulted in the mRNA and protein expression decrease of HDAC3 and CDK2 (Fig. 7g-h; Figure S7G-H).

\section{Suppression of HDAC3 and AKT are required for} chidamide induced anthracycline-resistant AML cells inhibition

To investigate whether chidamide-induced anthracyclineresistant AML cells inhibition was associated with the inactivation of HDAC3 in an AKT-dependent manner, we overexpressed HDAC3 or AKT after chidamide-induced leukemia inhibition. We found that overexpression of HDAC3 rescued the decreased cell viability (Fig. 8a), relieved cell cycle arrest (Fig. $8 \mathrm{~b}-\mathrm{c}$ ) and reduced the rate of

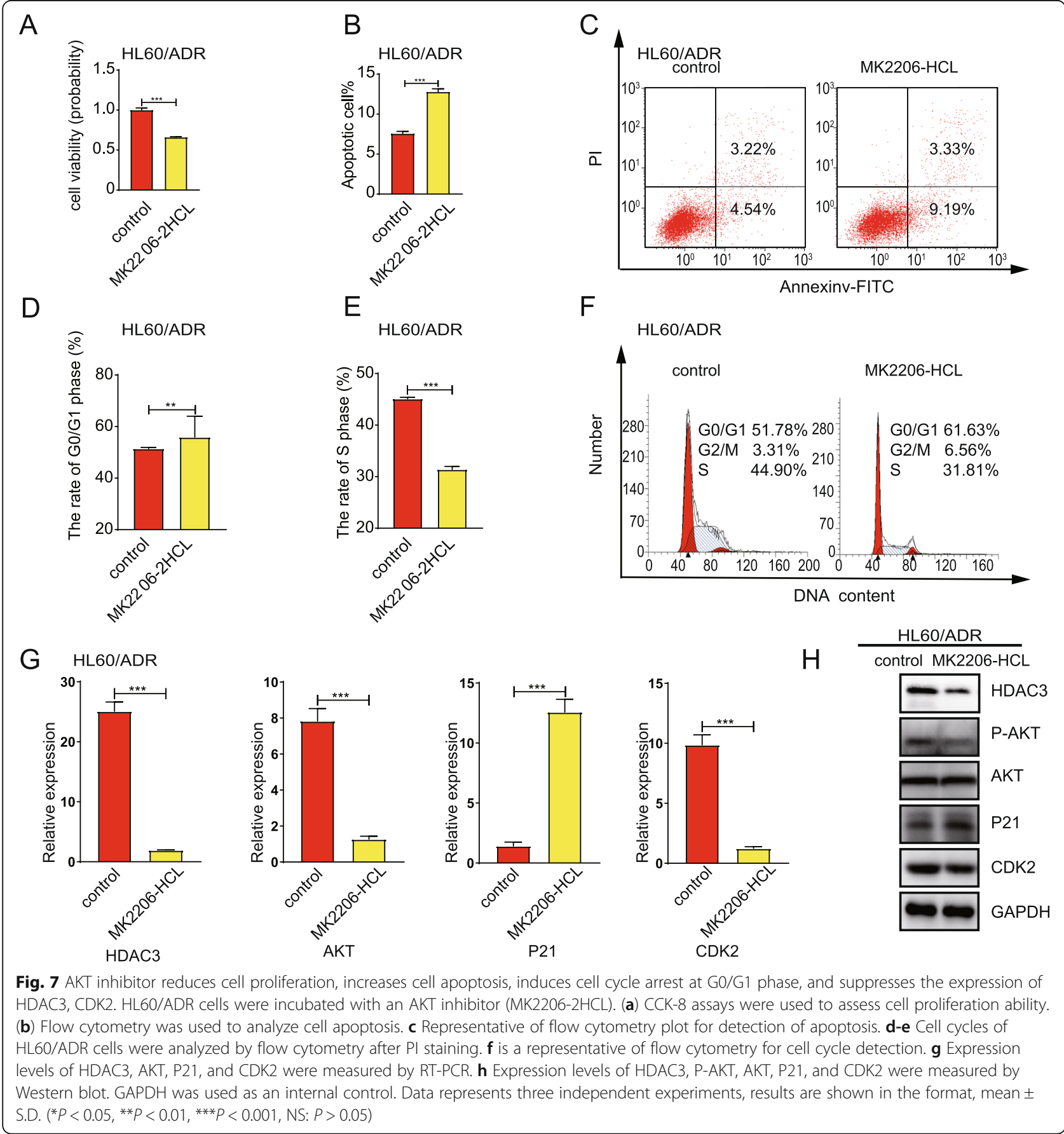




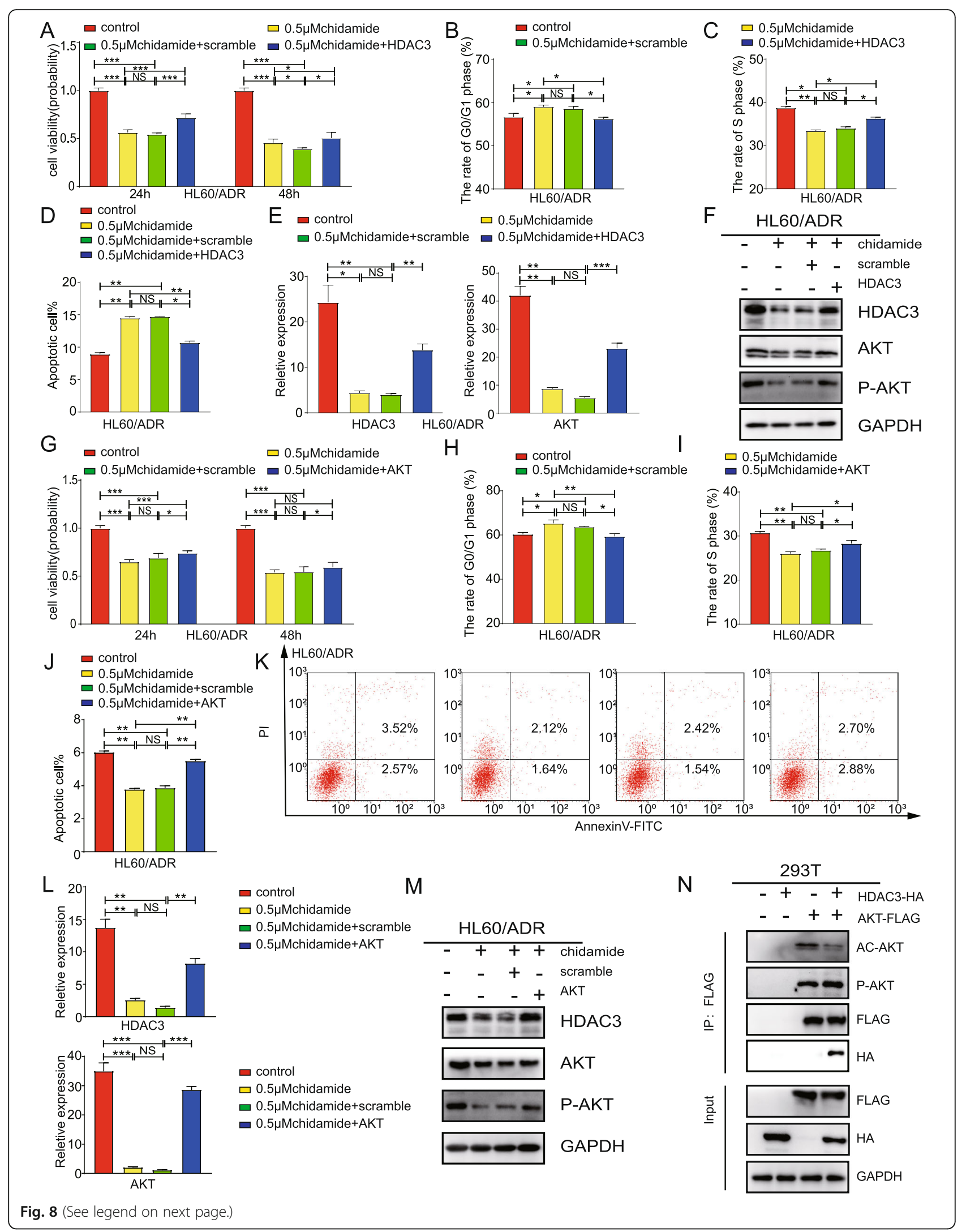


(See figure on previous page.)

Fig. 8 Suppression of HDAC3 and AKT are required for chidamide induced anthracycline-resistant AML cells inhibition. HL60/ADR cells were treated with chidamide for $48 \mathrm{~h}$ and transfected with overexpressed HDAC3 plasmids or control plasmids. a CCK-8 assays were used to assess cell proliferation ability. b-c Cell cycle detection by flow cytometry. $\mathbf{d}$ Detection of apoptosis by flow cytometry. The expression of HDAC3 and AKT was measured by RT-PCR (e) and western blot analysis ( $\mathbf{f})$ HL60/ADR cells were treated with chidamide for $48 \mathrm{~h}$ and transfected with overexpressed AKT plasmids or control plasmids. g CCK-8 assays were used to assess cell proliferation ability. h-i Cell cycle detection by flow cytometry. j-k Detection of apoptosis by flow cytometry. The expression of HDAC3 and AKT was measured by RT-PCR (I) and western blot analysis (m). $\mathbf{n}$ Co-immunoprecipitation of AKT and HDAC3 were performed in 293 T cells. Data represents three independent experiments, data are expressed as mean values \pm S.D. $\left({ }^{*} P<0.05,{ }^{*} P<0.01,{ }^{* *} P<0.001, \mathrm{NS}: P>0.05\right)$

apoptosis cells (Fig. 8d) induced by chidamide. In addition, overexpression of HDAC3 upregulated the chidamidedecreased AKT at mRNA level, and increased AKT phosphorylation (Fig. 8e-f). Silimarly, overexpression of AKT also restored cell viability (Fig. 8g), relieved cell cycle arrest (Fig. 8h-i) and reduced the rate of apoptosis cells (Fig. 8j-k).

HDAC3 binds AKT and increases the AKT phosphorylation while activated AKT contributes to HDAC3 expression

KC Hung had reported that activated AKT upregulated HDAC3 expression [26]. And we also showed that overexpression of $\mathrm{AKT}$ increased the $\mathrm{mRNA}$ and protein level of HDAC3 (Fig. 81-m). To elucidate the mechanism underlying HDAC3 and AKT circuit and whether HDAC3 is responsible for AKT phosphorylation, we performed co-immunoprecipitation to verify the HDAC3AKT interaction in HEK293T cells coexpressing HDAC3 and AKT. Co-immunoprecipitation demonstrated protein interaction of HDAC3 and AKT. The results of Western blotting with anti-acetylation and phosphorylation revealed a higher level of phosphorylation and lower acetylation in cells coexpressing HDAC3 and AKT compared to that in cells expressing AKT alone, which might result from endogenous HDAC3 (Fig. 8n). These results support the idea that HDAC3 binds AKT and increases the AKT phospharylation.

\section{Discussion}

Currently, the treatment for relapsed/refractory AML remains a major challenge. A drug or treatment regimen is required to improve the remission rates for $R / R$ to prolong overall survival time. It is necessary to discover the mechanism behind AML resistance, and find target drugs or regimens to overcome drug resistance, so as to improve the CR rate of patients with relapsed/refractory AML, prolong disease-free survival time and overall survival rates.

This study shown that the chidamide-based regimen improves the overall remision rate of patients with relapsed/refractory AML, so we want to further analyze the mechanism of bring such good clinical therapeutic results. To obtain a better understanding of the mechanism of drug resistance, we performed RNAsequencing in drug-resistant and control cells. From the results of RNA-sequencing, we found that the PI3KAKT signaling pathway was activated and HDAC3 was upregulated in drug-resistant cells.

Activated AKT regulated apoptosis, cell growth, and the cell-cycle through phosphorylation of numerous downstream targets [27]. Inhibition of the PI3K-AKT signaling pathway decreased leukemia stem cell growth and increased apoptosis [28, 29]. Moreover, the PI3K/ AKT signaling pathway is often hyperactive in AML patients with poor prognoses [28-30]. In several types of cancer, including AML, activation of the PI3K/AKT signaling pathway reduces sensitivity to chemotherapeutic drugs [31].

It was shown that the aberrant recruitment of HDACs plays an important role in leukemogenesis. Changes in activity and/or expression levels of HDACs were also observed in leukemia and solid tumors [32, 33]. Overexpression of HDACs in tumor cells was shown to protect cells from genotoxic insults [23]. For example, the expression of HDAC3 was shown to be vital to the maintenance of genome stability and DNA damage control. HDAC3 knockdown impaired DNA repair [34] and resulted in growth inhibition of human colon cancer cell lines [35]. Moreover, depletion or pharmacological inhibition of HDAC3 triggered apoptosis in cutaneous T-cell lymphoma and multiple myeloma [36, 37].

Previous studies have confirmed the close relationship between HDAC3 and AKT [24, 25]. HDAC3 binds to AKT in several cell lines, and regulates the phosphorylation and acetylation levels of AKT. Overexpression of HDAC3 reduces AKT acetylation levels but increases AKT phosphorylation levels.

Taking earlier research and this study into account, it is evident that HDAC3 and P-AKT expressions are positively correlated in drug-resistant $\mathrm{K} 562 / \mathrm{A} 02$ cells. In addition, activation of the HDAC3-AKT-P21-CDK2 pathway represents one of the mechanisms through which K562/A02 cells achieve resistance to anthracycline. Therefore, there is an urgent need for a drug to inhibit this signaling pathway and reverse drug resistance. Here, we found that chidamide inhibits cell 
proliferation, increases cell apoptosis, and induces cellcycle arrest in a time- and dose-dependent manner in anthracycline-resistant AML cells. These effects are associated with the inhibition of the HDAC3 -AKT-P21CDK2 signaling pathway.

Our study showed that expression levels of HDAC3 had increased in anthracycline-resistant cells. Univariate and multivariate analyses confirmed that HDAC3 had an adverse effect on OS and EFS. Our research showed that the HDAC inhibitor, chidamide also exhibited a significant inhibitory effect on anthracycline-resistant AML cell growth by suppressing HDAC3 expression. This result is consistent with another study that showed that chidamide inhibits pancreatic tumor growth by suppressing the expression of HDACs [38].

Cyclin-dependent kinases (CDKs) are a family of serine/threonine protein kinases that regulate cell cycle progression [39]. CDK2 activity is necessary for cells to progress through the $S$ phase $[40,41]$. CDKs are inhibited by CDK inhibitors (CKIs) [42], such as P21, which suppresses CDK2 activity and blocks cell cycle transition from G1 phase to $S$ phase [43-45]. Moreover, the expression of P21 has always been regulated by HDAC inhibitors [38, 46, 47] and P21 is upregulated following HDAC3 depletion [48]. In this study, the HDAC inhibitor, chidamide induced cell-cycle arrest in a time- and dose-dependent manner in anthracycline-resistant AML cells. The mechanism of action may be through the inhibition of CDK2 expression and increase in P21 expression.

Patients who are resistant to primary chemotherapy or have relapsed have poor prognoses due to the inability to control disease progression and therapeutic complications. Histone deacetylases (HDACs) are responsible for the regulation of gene transcription, protein function, and stability [49, 50]. HDAC inhibitors are able to potently induce cell cycle arrest, differentiation, and apoptosis of malignant cells [51]. HDAC inhibitors have been used in the treatment of several hematologic tumors, such as acute myeloid leukemia and T-cell lymphomas [52-62]. In the present study, 27 patients who experienced $\mathrm{R} / \mathrm{R}$ after receiving anthracycline therapy were given a combination of chidamide and anthracycline-based regimen. The combination of chidamide and anthracycline increases the sensitivity of leukemia cells to anthracyclines and is able to reverse drug resistance.

\section{Conclusion}

In summary, our study showed that The combination of chidamide and anthracycline-based regimen is a promising treatment for $\mathrm{R} / \mathrm{R}$ patients. The abnormality of the HDAC3-AKT-P21-CDK2 signaling pathway may be one of the mechanisms through which AML cells achieve anthracycline resistance. Chidamide inhibits cell proliferation, as well as induces cell-cycle arrest and apoptosis in a time- and dose-dependent manner in R/R AML cells. These effects are associated with an inhibition of the HDAC3-AKT-P21CDK2 pathway.

\section{Supplementary Information}

The online version contains supplementary material available at https://doi. org/10.1186/s13046-020-01792-8.

Additional file 1: Supplemental Figure 1. Anthracycline-resistant cell lines HL60/ADR cells, K562/A02 cells and THP/ADR cells showed resistance to doxorubicin. Cell viability was examined after treatment with different doses of doxorubicin for $24 \mathrm{~h}$ by CCK-8 assay. (A) HL60, (B) HL60/ ADR, (C) K562, (D) K562/A02, (E) THP-1, (F) THP-1/ADR. Supplemental Figure 2. Differential gene and protein expression in K562 and K562/A02. (A) RT-PCR analysis showed differential gene expression in K562 and K562/A02. (B) Western blot analysis shows protein expression of differential gene in K562 and K562/A02. Data represent three independent experiments, results are shown in the format, mean \pm S.D. $\left({ }^{*} P<0.05,{ }^{*} P<0.01\right.$, ${ }^{* * *} P<0.001$, NS: $\left.P>0.05\right)$. Supplemental Figure 3. Chidamide sensitizes anthracycline-resistant cells to anthracycline in vivo. (A) K562 cells ( $1 \times$ $10^{7}$ cells) were implanted into NOD/SCID mice. The mice were randomly divided into 4 groups (5 mice in each group). Doxorubicin was injected into the mice at day 5 and day 12 after leukemic cells inoculation. And chidamide was administered 3 times every week from day 6 after leukemic cells inoculation. (B) The volume of each tumor was measured every 3 days. The tumor volume was calculated by the formula $(V=$ $0.5^{*}$ length* ${ }^{*}$ width $^{2}$ ). (C) The visual analysis of tumors harvested from mice. (D-E) The measurement of xenograft tumor volume and weight. (F) The mRNA expression levels of HDAC3, AKT, P21 and CDK2 were measured using RT-PCR in tumor sections. Data represent three independent experiments, data are expressed as mean values \pm S.D. $\left({ }^{*} P<0.05\right.$, ${ }^{*} P<0.01$, $\left.{ }^{* * *} P<0.001, N S: P>0.05\right)$. Supplemental Figure 4A-I. Chidamide affected the behavior of anthracycline- resistant cells. (A) CCK-8 assays were used to assess the proliferative abilities of K562/A02 cells. The proportion of $\mathrm{G} 0 / \mathrm{G} 1$ phase (B) and S phase (C) were measured in response to incubation with chidamide in K562/A02 cells. The proportion of G0/G1 phase (D) and S phase (E) were measured in THP-1/ADR cells. (F-G) represent apoptosis analysis with flow cytometry in K562/A02 cells and (H-I) in THP-1/ADR cells (Annexin V/PI). Data represent three independent experiments, results are shown in the format, mean \pm S.D. $\left({ }^{*} P<0.05\right.$, ${ }^{*} P<$ 0.01 , ${ }^{* *} P<0.001$, NS: $P>0.05$ ). Supplemental Figure 4J-W. K562, HL60 and patient-derived anthracycline-sensitive AML cells are sensitive to chidamide monotherapy, and chidamide sensitizes anthracyclineresistant cells to anthracycline in K562/A02 and THP/ADR cells. CCK-8 assays were used to assess the proliferative abilities of K562 (J), HL60 (K), patient-derived cells $\mathbf{( L )}$. (M-N) are representatives of flow cytometry (Annexin V/PI) for detection of apoptosis. The apoptotic rate of cells was measured by flow cytometry in K562 (0) and HL60 cells (P). (Q-R) represent cell cycle analysis with flow cytometry in K562 cells and HL60 cells. The proportion of G0/G1 phase and S phase were measured in response to incubation with chidamide in K562 cells (S) and HL60 cells (T). The cell viability of (U) K562/A02 and (V) THP-1/ADR cells treated by combination therapy were measured with CCK-8 assays. (W) HDAC activity of K562/ A02 cells was measured after treated with chidamide. Data represent three independent experiments, results are shown in the format, mean \pm S.D. $\left({ }^{*} P<0.05,{ }^{* *} P<0.01,{ }^{* *} P<0.001\right.$, NS: $\left.P>0.05\right)$. Supplemental Figure 5. Molecular mechanisms of chidamide activity in K562/A02 and THP-1/ADR cells. Anthracycline-resistant AML cells were treated with different concentrations of chidamide. Expression levels of HDAC3, AKT, P21 and CDK2 were measured using RT-PCR in K562/A02 cells (A) and THP-1/ ADR cells (B). (C) K562/A02 and (D) THP-1/ADR were treated with chidamide and the expression levels of HDAC3, P-AKT, AKT, P21 and CDK2 were measured by Western blot. RT-PCR analysis of HDAC3, AKT, CDK2 
and P21 (E) and western blot analysis (F) in K562/ADR cells treated with a combination of chidamide and doxorubicin. The expression of pathway genes was measured by RT-PCR (G) and Western blot (H) in THP-1/ADR cells treated with combination therapy. Data represent three independent experiments, and results are shown in the format, means \pm S.D. $\left({ }^{*} P<\right.$ $\left.0.05,{ }^{*} P<0.01,{ }^{* * *} P<0.001\right)$. Figure S6. Transfection with HDAC3 shRNA in K562/A02 cells reduces cell proliferation, increases cell apoptosis, induces cell cycle arrest at G0/G1 phase, and suppresses AKT-P21-CDK2 signaling pathways. (A) CCK-8 assays were used to assess cell proliferation ability. (B) Cell apoptosis was analyzed after HDAC3 knockdown by flow cytometry using Annexin-V/PI staining. (C) is a representative of flow cytometry plot for detection of apoptosis. (D-E) Cell cycles of K562/A02 cells were analyzed by flow cytometry after PI staining. (F) is a representative of flow cytometry for cell cycle detection. (G) Expression levels of HDAC3, AKT, P21 and CDK2 were measured by RT-PCR. (H) Expression levels of HDAC3, P-AKT, AKT, P21 and CDK2 were measured by Western blot. GAPDH was used as an internal control. Data represent three independent experiments, and results are shown in the format, mean \pm S.D. $\left.{ }^{*} P<0.05,{ }^{*} P<0.01,{ }^{* * *} P<0.001, N S: P>0.05\right)$. Figure S7. AKT inhibitor reduces cell proliferation, increases cell apoptosis, induces cell cycle arrest at G0/G1 phase, and suppresses the expression of HDAC3, CDK2 and P21. K562/A02 cells were incubated with an AKT inhibitor (MK2206-2HCL). (A) CCK-8 assays were used to assess cell proliferation ability. (B) Flow cytometry was used to analyze cell apoptosis. (C) is a representative of flow cytometry plot for detection of apoptosis. (D-E) Cell cycles of K562/A02 cells were analyzed by flow cytometry after PI staining. (F) is a representative of flow cytometry for cell cycle detection. (G) Expression levels of HDAC3, AKT, P21 and CDK2 were measured by RT-PCR. (H) Expression levels of HDAC3, P-AKT, AKT, P21 and CDK2 were measured by Western blot. GAPDH was used as an internal control. Data represent three independent experiments, results are shown in the format, mean \pm S.D. ${ }^{*} P<$ $0.05,{ }^{* *} P<0.01,{ }^{* * *} P<0.001$, NS: $\left.P>0.05\right)$. Table S1.Comparison of different anthracycline-based chemotherapy regimens.

\section{Abbreviations}

AML: Acute myeloid leukemia; R/R: Relapse or refractory; EFS: Event free survival; OS: Overall survival; HDAC3: Histone deacetylase 3; AKT: AKT serine/ threonine kinase 1; P21: P21 calcium binding protein; CDK2: Cyclin dependent kinase 2; PI3K: Phosphoinositide 3-kinase; CR: Complete remission; HDAC: Histone deacetylase; NCCN: The National Comprehensive Cancer Network; DAC: Decitabine; Acla: Aclarubicin; Arac: Cytarabine; GCSF: Granulocyte colony stimulating factor; VP: Vincristine and prednisone; RPKM: Reads per kilobase per million mapped reads; TCGA: The Cancer Genome Atlas database; ATCC: America type culture collection; RPMI 1640: Roswell Park Memorial Institute 1640; DMEM: Dulbecco's modified eagle medium; FBS: Fetal bovine serum; PBMCs: Peripheral blood mononuclear cells; CCK-8: Cell Counting Kit-8; PI: Propidium lodide; FITC: Fluorescein Isothiocyanate; RT-PCR: Real time polymerase chain reaction; SDS-PAGE: Sodium dodecyl sulfate polyacrylamide gel electrophoresis; NOD/SCID: Nod-obese diabetic/severecombined immunodeficiency disease: KEGG: Kyoto Encyclopedia of Genes and Genomes; GO: Gene ontology; FLT3/ITD: Fms-like tyrosine kinase internal tandem duplication; DNMT3A: Recombinant DNA methyltransferase 3A; BCOR: BCL6 corepressor; NRAS: N-ras oncogene; STAG2: Stromal antigen 2; PFS: Progression-free survival; WBC: White blood cell; Doxo: Doxorubicin; Chi: Chidamide

\section{Acknowledgments}

Not applicable.

\section{Authors' contributions}

CYZ performed the research and wrote the manuscript. CYZ, YCL, HW, MZW, XSC performed the research. XKW performed the statistical analysis. LPD, CJG, SJL, FY, BXP, YHL and DHL designed and supervised the research project. The authors read and approved the final manuscript.

\section{Funding}

This work was partially supported by grants from the Beijing Nova Program (2011114), the National Natural Science Foundation of China (No. 82070178), the Beijing Natural Science Foundation of China (No. 7172200, and 7132217), the
Capital's Funds for Health Improvement and Research (No. 2016-1-4082), the Fund Sponsorship of the Capital Public Health Project for DH Liu, National Key Clinical Specialized Military Construction Project for DH Liu (Clinical Medicine), and Hainan Provincial Natural Science Foundation of China (818MS157). Military Translational Medicine Fund of Chinese PLA General Hospital (ZH19003). Medical big data and artificial intelligence development fund of Chinese PLA General Hospital (2019MBD-016). This work was partially supported by grants from the National Institutes of Health/National Cancer Institute (R01CA149623, R21CA155915, and R03CA186176), the Hormel Foundation.

\section{Availability of data and materials}

All data generated or analyzed during this study are included in this published article.

\section{Ethics approval and consent to participate}

This study has been approved by the Ethics Committee and written informed consentwas obtained from all participants.

\section{Consent for publication}

The authors declare that they consent for publication.

\section{Competing interests}

The authors declare that they have no competing interests.

\section{Author details}

'Department of Hematology, Chinese People's Liberation Army (PLA) General Hospital, 28 Fuxing Road, Beijing 100853, China. ${ }^{2}$ State Key Laboratory of Inorganic Synthesis and Preparative Chemistry, International Joint Research Laboratory of Nano-Micro Architecture Chemistry (NMAC), International Research Center for Chemistry-Medicine Joint Innovation, College of Chemistry, Jilin University, 2699 Qianjin Street, Changchun 130012, China. ${ }^{3}$ School of Medicine, Nankai University, 94 Weijin Road, Tianjin 300071, China. ${ }^{4}$ Department of Orthopedics, Xiqing Hospital, 403 Xiqing Road, Yangliuqing, Tianjin 300000, China. ${ }^{5}$ Department of Cell and Chemical Biology, Leiden University Medical Center, Leiden, the Netherlands. ${ }^{6}$ The Hormel Institute, University of Minnesota, 801 16th Avenue NE, Austin, MN 55912, USA.

Received: 29 January 2020 Accepted: 26 November 2020

Published online: 09 December 2020

\section{References}

1. Jabbour EJ, Estey E, Kantarjian HM. Adult acute myeloid leukemia. Mayo Clin Proc. 2006;81:247-60.

2. Lowenberg B, Ossenkoppele GJ, van Putten W, et al. High-dose daunorubicin in older patients with acute myeloid leukemia. N Engl J Med. 2009;361:1235-48.

3. Dohner H, Estey E, Grimwade D, et al. Diagnosis and management of AML in adults: 2017 ELN recommendations from an international expert panel. Blood. 2017;129:424-47.

4. Schlenk RF, Frech $P$, Weber $D$, et al. Impact of pretreatment characteristics and salvage strategy on outcome in patients with relapsed acute myeloid leukemia. Leukemia. 2017:31:1217-20.

5. Dombret H, Gardin C. An update of current treatments for adult acute myeloid leukemia. Blood. 2016;127:53-61.

6. Othus M, Appelbaum FR, Petersdorf $\mathrm{SH}$, et al. Fate of patients with newly diagnosed acute myeloid leukemia who fail primary induction therapy. Biol Blood Marrow Transplant. 2015;21:559-64.

7. Estey E, Kornblau S, Pierce S, Kantarjian H, Beran M, Keating M. A stratification system for evaluating and selecting therapies in patients with relapsed or primary refractory acute myelogenous leukemia. Blood. 1996;88:756.

8. Estey EH. Treatment of relapsed and refractory acute myelogenous leukemia. Leukemia. 2000;14:476-9.

9. Thol F, Schlenk RF, Heuser M, Ganser A. How I treat refractory and early relapsed acute myeloid leukemia. Blood. 2015;126:319-27.

10. Chiba T, Yokosuka O, Fukai $\mathrm{K}$, et al. Cell growth inhibition and gene expression induced by the histone deacetylase inhibitor, trichostatin a, on human hepatoma cells. Oncology. 2004;66:481-91.

11. de Ruijter AJ, Meinsma RJ, Bosma P, Kemp S, Caron HN, van Kuilenburg AB. Gene expression profiling in response to the histone deacetylase inhibitor BL1521 in neuroblastoma. Exp Cell Res. 2005;309:451-67. 
12. Liu L, Chen B, Qin S, et al. A novel histone deacetylase inhibitor Chidamide induces apoptosis of human colon cancer cells. Biochem Biophys Res Commun. 2010;392:190-5.

13. Dong M, Ning ZQ, Xing PY, et al. Phase I study of chidamide (CS055/HBI8000), a new histone deacetylase inhibitor, in patients with advanced solid tumors and lymphomas. Cancer Chemother Pharmacol. 2012;69:1413-22.

14. Zhou Y, Pan DS, Shan S, et al. Non-toxic dose chidamide synergistically enhances platinum-induced DNA damage responses and apoptosis in nonsmall-cell lung cancer cells. Biomed Pharmacother. 2014;68:483-91.

15. Gong K, Xie J, Yi H, Li W. CS055 (Chidamide/HBI-8000), a novel histone deacetylase inhibitor, induces G1 arrest, ROS-dependent apoptosis and differentiation in human leukaemia cells. Biochem J. 2012;443:735-46.

16. Shi $Y$, Jia $B, X u W$, et al. Chidamide in relapsed or refractory peripheral $T$ cell lymphoma: a multicenter real-world study in China. J Hematol Oncol. 2017;10:69.

17. He M, Qiao Z, Wang Y, et al. Chidamide inhibits aerobic metabolism to induce pancreatic cancer cell growth arrest by promoting Mcl-1 degradation. PLoS One. 2016;11:e0166896.

18. Hu X, Wang L, Lin L, et al. A phase I trial of an oral subtype-selective histone deacetylase inhibitor, chidamide, in combination with paclitaxel and carboplatin in patients with advanced non-small cell lung cancer. Chin Cancer Res. 2016;28:444-51.

19. Zhao S, Guo J, Zhao Y, et al. Chidamide, a novel histone deacetylase inhibitor, inhibits the viability of MDS and AML cells by suppressing JAK2/ STAT3 signaling. Am J Transl Res. 2016;8:3169-78.

20. Ley TJ, Miller C, Ding $L$, et al. Genomic and epigenomic landscapes of adult de novo acute myeloid leukemia. N Engl J Med. 2013;368:2059-74.

21. Yang CZ, Luan FJ, Xiong DS, Liu BR, Xu YF, Gu KS. Multidrug resistance in leukemic cell line K562/A02 induced by doxorubicin. Zhongguo Yao Li Xue Bao. 1995;16:333-7.

22. Cress WD, Seto E. Histone deacetylases, transcriptional control, and cancer. J Cell Physiol. 2000;184:1-16.

23. Eot-Houllier G, Fulcrand G, Magnaghi-Jaulin L, Jaulin C. Histone deacetylase inhibitors and genomic instability. Cancer Lett. 2009;274:169-76.

24. Gupta M, Ansell SM, Novak AJ, Kumar S, Kaufmann SH, Witzig TE. Inhibition of histone deacetylase overcomes rapamycin-mediated resistance in diffuse large B-cell lymphoma by inhibiting Akt signaling through mTORC2. Blood. 2009;114:2926-35.

25. Bradley EW, Carpio LR, Westendorf JJ. Histone deacetylase 3 suppression increases PH domain and leucine-rich repeat phosphatase (Phlpp)1 expression in chondrocytes to suppress Akt signaling and matrix secretion. Biol Chem. 2013;288:9572-82.

26. Hung K-C, Lin M-L, Hsu S-W, et al. Suppression of Akt-mediated HDAC3 expression and CDK2 T39 phosphorylation by a bichalcone analog contributes to S phase retardation of cancer cells. Eur J Pharmacol. 2018:829:141-50.

27. Vivanco I, Sawyers CL. The phosphatidylinositol 3-kinase AKT pathway in human cancer. Nat Rev Cancer. 2002;2:489-501.

28. Grandage VL, Gale RE, Linch DC, Khwaja A. PI3-kinase/Akt is constitutively active in primary acute myeloid leukaemia cells and regulates survival and chemoresistance via NF-kappaB, Mapkinase and p53 pathways. Leukemia. 2005;19:586-94

29. Xu Q, Simpson SE, Scialla TJ, Bagg A, Carroll M. Survival of acute myeloid leukemia cells requires PI3 kinase activation. Blood. 2003;102:972-80.

30. Min YH, Eom Jl, Cheong JW, et al. Constitutive phosphorylation of Akt/PKB protein in acute myeloid leukemia: its significance as a prognostic variable. Leukemia. 2003;17:995-7.

31. West KA, Castillo SS, Dennis PA. Activation of the PI3K/Akt pathway and chemotherapeutic resistance. Drug Resist Updat. 2002;5:234-48.

32. Minucci S, Pelicci PG. Histone deacetylase inhibitors and the promise of epigenetic (and more) treatments for cancer. Nat Rev Cancer. 2006;6:38-51.

33. Bolden JE, Peart MJ, Johnstone RW. Anticancer activities of histone deacetylase inhibitors. Nat Rev Drug Discov. 2006;5:769-84.

34. Bhaskara S, Knutson SK, Jiang G, et al. Hdac3 is essential for the maintenance of chromatin structure and genome stability. Cancer Cell. 2010;18:436-47.

35. Wilson AJ, Byun DS, Popova N, et al. Histone deacetylase 3 (HDAC3) and other class I HDACs regulate colon cell maturation and p21 expression and are deregulated in human colon cancer. J Biol Chem. 2006;281:13548-58.

36. Minami J, Suzuki R, Mazitschek R, et al. Histone deacetylase 3 as a novel therapeutic target in multiple myeloma. Leukemia. 2014;28:680-9.

37. Wells CE, Bhaskara S, Stengel KR, et al. Inhibition of histone deacetylase 3 causes replication stress in cutaneous T cell lymphoma. PLoS One. 2013;8:e68915.
38. Zhao B, He T. Chidamide, a histone deacetylase inhibitor, functions as a tumor inhibitor by modulating the ratio of Bax/Bcl-2 and P21 in pancreatic cancer. Oncol Rep. 2015;33:304-10.

39. Malumbres M. Cyclin-dependent kinases. Genome Biol. 2014;15:122.

40. Woo RA, Poon RY. Cyclin-dependent kinases and S phase control in mammalian cells. Cell Cycle. 2003;2:316-24.

41. Peiretti A, Baghdassarian N, Gerland LM, et al. CDK2 is involved in the Sphase lengthening induced by glucocorticoids in normal human lymphocytes. Eur J Cell Biol. 2003;82:253-61.

42. Vermeulen K, Van Bockstaele DR, Berneman ZN. The cell cycle: a review of regulation, deregulation and therapeutic targets in cancer. Cell Prolif. 2003; 36:131-49.

43. Warfel NA, El-Deiry WS. p21WAF1 and tumourigenesis: 20 years after. Curr Opin Oncol. 2013;25:52-8.

44. Stivala LA, Cazzalini O, Prosperi E. The cyclin-dependent kinase inhibitor p21CDKN1A as a target of anti-cancer drugs. Curr Cancer Drug Targets. 2012;12:85-96.

45. Kizildag S, Ates H, Kizildag S. Treatment of K562 cells with 1,25-dihydroxyvitamin D3 induces distinct alterations in the expression of apoptosis-related genes BCL2, BAX, BCLXL, and p21. Ann Hematol. 2010;89:1-7.

46. Richon VM, Sandhoff TW, Rifkind RA, Marks PA. Histone deacetylase inhibitor selectively induces p21WAF1 expression and gene-associated histone acetylation. Proc Natl Acad Sci U S A. 2000;97:10014-9.

47. Frys $\mathrm{S}$, Simons Z, Hu Q, et al. Entinostat, a novel histone deacetylase inhibitor is active in B-cell lymphoma and enhances the anti-tumour activity of rituximab and chemotherapy agents. Br J Haematol. 2015;169:506-19.

48. Spurling CC, Godman CA, Noonan EJ, Rasmussen TP, Rosenberg DW, Giardina C. HDAC3 overexpression and colon cancer cell proliferation and differentiation. Mol Carcinog. 2008;47:137-47.

49. Caron C, Boyault C, Khochbin S. Regulatory cross-talk between lysine acetylation and ubiquitination: role in the control of protein stability. Bioessays. 2005;27:408-15.

50. Sengupta N, Seto E. Regulation of histone deacetylase activities. J Cell Biochem. 2004;93:57-67.

51. Ververis K, Hiong A, Karagiannis TC, Licciardi PV. Histone deacetylase inhibitors (HDACls): multitargeted anticancer agents. Biologics. 2013;7:47-60.

52. Olsen EA, Kim YH, Kuzel TM, et al. Phase Illb multicenter trial of vorinostat in patients with persistent, progressive, or treatment refractory cutaneous Tcell lymphoma. J Clin Oncol. 2007;25:3109-15.

53. Duvic M, Talpur R, Ni X, et al. Phase 2 trial of oral vorinostat (suberoylanilide hydroxamic acid, SAHA) for refractory cutaneous T-cell lymphoma (CTCL). Blood. 2007;109:31-9.

54. Odenike OM, Alkan S, Sher D, et al. Histone deacetylase inhibitor romidepsin has differential activity in core binding factor acute myeloid leukemia. Clin Cancer Res. 2008;14:7095-101.

55. Piekarz RL, Frye $\mathrm{R}$, Turner $\mathrm{M}$, et al. Phase II multi-institutional trial of the histone deacetylase inhibitor romidepsin as monotherapy for patients with cutaneous T-cell lymphoma. J Clin Oncol. 2009:27:5410-7.

56. Whittaker SJ, Demierre MF, Kim EJ, et al. Final results from a multicenter international, pivotal study of romidepsin in refractory cutaneous T-cell lymphoma. J Clin Oncol. 2010;28:4485-91.

57. Piekarz RL, Frye R, Prince HM, et al. Phase 2 trial of romidepsin in patients with peripheral T-cell lymphoma. Blood. 2011;117:5827-34.

58. Ellis L, Pan Y, Smyth GK, et al. Histone deacetylase inhibitor panobinostat induces clinical responses with associated alterations in gene expression profiles in cutaneous T-cell lymphoma. Clin Cancer Res. 2008;14:4500-10.

59. Johnstone RW, Licht JD. Histone deacetylase inhibitors in cancer therapy: is transcription the primary target? Cancer Cell. 2003;4:13-8.

60. Dokmanovic M, Marks PA. Prospects: histone deacetylase inhibitors. J Cell Biochem. 2005;96:293-304

61. Acharya MR, Sparreboom A, Venitz J, Figg WD. Rational development of histone deacetylase inhibitors as anticancer agents: a review. Mol Pharmacol. 2005;68:917-32.

62. Drummond DC, Noble CO, Kirpotin DB, Guo Z, Scott GK, Benz CC. Clinical development of histone deacetylase inhibitors as anticancer agents. Annu Rev Pharmacol Toxicol. 2005:45:495-528.

\section{Publisher's Note}

Springer Nature remains neutral with regard to jurisdictional claims in published maps and institutional affiliations. 